\title{
Palinodia y bofetón
}

\author{
por Xuan Xosé Sánchez Vicente
}

\begin{abstract}
Antoxana...
Tel AÑu 20I5, cuando tenía casi perfechu un comentariu d'El caba1 llu de Benavides, la Biblioteca d'Asturies fízose con una mozadina de manuscritos, xuntos nun llibru fácticu, que proveníen de la biblioteca del bibliófilu arxentinu García Donnel, quien lu comprara en Madrid a finales del XIx. El casu ye qu'ente esos manuscritos taba ún d'El caballu, que presentaba numeroses variantes al respective del editáu por Caveda en I839. Como resultes d'ello y teniendo en cuenta además les variantes del nuestru testu qu'apaecíen nel Diccionario de algunas voces del dialecto asturiano de González Posada ${ }^{1}$, la mio edición del poema en $2016^{2}$ tenía desinfinidá de notes a pie de páxina, bien señalando variaciones mor-

${ }^{1}$ Marino Busto (1986) = Marino Busto, Diccionario bable de González Posada y Academia Asturiana de Letras, con prólogu de Jesús Neira Martínez y epílogu de Jesús Evaristo Casariego. Uviéu, Biblioteca Literaria Asturiana, Instituto de Estudios Asturianos, Uviéu, 1986. GonZÁLEZ De Posada (1989) = Carlos GonzÁlez De Posada, Diccionario de algunas voces del dialecto asturiano (I778) y otros papeles. Edición de X. Ll. García Arias. Biblioteca de Filoloxía Asturiana, Universidá d'Uviéu, Uviéu, 1989.

2 Bernaldo de Quirós y Benavides (20I6) = Francisco Bernaldo de Quirós y Benavides, El caballu, edición anotada de Xuan Xosé Sánchez Vicente, ediciones Saltadera, col. La Vieya Zuna, n. ${ }^{\circ}$, Uviéu, 2016.
\end{abstract}


folóxiques o léxiques, bien tratando d'interpretar o reordenar aspectos escuros del testu.

D'ente les palabres qu'apaecíen nel poema y que yo comentaba taba fobetones, qu'apaez nel versu 77, nesta frase: Fobetones da á les piedres I que les estriza en migayes. El vocablu yera aparentemente un hápax. Yo nun lu conocía, nin l'Academia nin otros diccionarios lu traíen; el DGLLA sí, pero ensin definición y cola única referencia al testu de Benavides.

El significáu de la palabra (nun contestu, además, nel que se significa la fuerza del caballu arreventando lo que pisa) yera claru, 'golpes', como lo yera la so relación col castellanu y asturianu actuales bofetones, polo que seguramente esi sería'l significáu primariu de la palabra: 'bofetada', 'bofetón', y, solo secundariamente o por derivación, 'golpe'. Agora bien, ¿cuála yera la relación ente bofetón y fobetón? ¿Yera l'hápax de fobetón un tracamundiu? Dempués de da-y vueltes y más vueltes a la cuestión llegué a proponer bofetones como la llectura bona del poema (Bofetones da á les piedres / que les estriza en migayes) y di la siguiente esplicación a pie de páxina:

Proponemos: Bofetones [Caveda: Fobetones]. En MBA lleo fofetones. En cualquier casu, la segunda consonante nun ye una «b» y sí, de xuru, una «f». El Fobetones de Caveda y Canella ye una singularidá nel conxuntu de léxicu asturianu y, por supuestu, yelo'l fofetones. Nun veo, además, la posibilidá d'arreyalu con ningún otru lexema peninsular. ¿Por qué, entós, nun suponer, cenciellamente, un tracamundiu na tresmisión testual de Caveda y de MBA? Digo esto último porque Posada, que trabaya fundamentalmente sobre materiales lliterarios y folklóricos, nun recueye la palabra, cuando yera razonable que la recoyere pa "traducila», como otres tantes; incluso pa intentar da-y una desplicación, como pudo facer col «destruyar» de la nota anterior. Más entovía, Posada, nel so "Voces del Dialecto asturiano" apunta, según tenemos dicho, munches pallabres d'El caballu. Pues bien, d'unes da'l significáu y d'otres non, yá fuere porque nun lo tenía claro, yá porque pensase dexalo pa más alantre. En concreto, ente les páxines 36 y 37 da una riestra de $4 \mathrm{I}$ vocablos seguíos que correspuenden casi toos al testu de Quirós y Benavides, ente los que, 
como diximos, hai dalgunos por definir, asina estos: reborbogar, escadiernes (debe ser l'escadiornes d'El caballu), brunes, cutrales, esmuergar, xirigates, destapinar, marniegos, esmuergar, cerbiones (debe ser el corbiones d'El caballu)... ¿Por qué, entós, de ser una palabra estraña, fobetones o fofetones, nun apuntala, masque fuere ensin da-y desplicación? Nun ye un argumentu definitivu, reconózolo, pero creo que refuerza la hipótesis de qu'envede tar delantre un casu únicu, fobetones, tamos delantre un tracamundiu, bofetones.

\section{...Y PALINODIA}

El domingu 24 de xunetu d'esti añu que cuerre (y antaína), con motivu d'una mesa redonda que sobre les xírigues y el tamargu diba celebrase'l xueves 27 en Llanes, púnxime a repasar dellos materiales. Ún d'ellos fui buscalu al númberu II/12 (20II/20I2) de la Revista de Filoloxía Asturiana, el «Vocabulario de eusquerismos en las jergas gremiales de Asturias y del noroeste de la Península (y II)». Y ellí, al delláu, atopábase ún de Xuan Carlos Busto Cortina, «Dos poetes de la primera metada del xviri: Xuan Fernández Porléi y Nicolás Torano de la Puerta»’, que, como'l de Ramón d'Andrés, yá lleera nel so momentu.

Dempués de repasar el de D’Andrés, volví mirar el de Busto y ellí afayo, atribuíu a Xuan Fernández Porléi, la Relación de un aldeano, un romance de 357 versos, nel que topo fobetón nel versu 270, nesta frase: Diome Xuan un fobetón / que me fexo esfocicar, I vi les estrelles nel suelu...

Yera evidente entós que'l fobetón d'El caballu nun yera una estrella solitaria, lo mesmo que lo yera'l que significaba equí 'bofetón', el so significáu primariu, como talantábamos. Pero lo más grave yera que

${ }^{3}$ ANDrÉs (2OII-2OI2) = RAMÓn D’ANDRÉs, «Vocabulario de eusquerismos en las jergas gremiales de Asturias y del noroeste de la Península (y II)». Busto (2OII-2OI2) = Xuan Carlos Busto Cortina, «Dos poetes de la primera metada del xviri: Xuan Fernández Porléi y Nicolás Torano de la Puerta». Dambos en Revista de Filoloxía Asturiana, volumen II/I2, años 20II/20I2, Trabe, Uviéu, 20I2. Los artículos de Ramón d'Andrés y de Xuan Carlos Busto ocupen, respectivamente, les páxines 8I a IIO y 9 a 48 . 
Busto facía referencia a dos ediciones anteriores del mesmu poema, les dos asoleyaes na colección «Cartafueyos de Lliteratura Escaecida» de l'Academia.

La primera, estudiada y editada por Álvaro Arias $\mathrm{Cabal}^{4}$, reproduz un manuscritu de solo iIs versos; la segunda, fecha por Xurde Blanco, ún que tien el mesmu númberu de versos que'l qu'edita Busto nel añu 20I2, 357. Y equí vien la mio confesión: yo non solo tenía lleíos aquellos testos nel so día, del mesmu mou que’l de Busto, sinón que, con un sistema d'anotación habitual en mi, mui rápidu y eficaz pero un daqué xostrón, el doblaxe de la páxina, yá tenía marcada la que contenía'l versu 270, onde taba, naturalmente, la palabra fobetones.

De modu y manera que, siguiendo cola palinodia y tornando al presente, nun nos topamos con un hápax, sinón con una palabra suficientemente contrastada que ta emparentada col asturianu modernus y castellanu bofetón y que tien el mesmu significáu primariu qu'esti, 'bofetada fuerte', y un secundariu, 'golpe'.

La etimoloxía de bofetón, como deriváu de bofetada, establécenla Corominas y Pascual $^{6}$, en bofar, que derivaría d'una onomatopeya y que, per mediu del antiguu bofete, daría dempués bofetada y, d'esta, bofetón. La RAE (s.v. bofetada) nun se compromete tanto y diz: «De or. inc.; cf. ingl. buffet 'puñetazo, manotazo'».

4 Arias Cabal (1996) = Álvaro Arias Cabal, Relación de un aldeano llamado Francisco Fernández por mote de la Candonga (I837), Academia de la Llingua Asturiana (Cartafueyos de Lliteratura escaecida, n. ${ }^{\circ}$ I2), Uviéu, I996. Blanco (1997) = Xurde Blanco, Pachu de la Candonga (I837), Academia de la Llingua Asturiana (Cartafueyos de Lliteratura escaecida, n. $\left.{ }^{\circ} 27\right)$, Uviéu, 1997.

5 El diccionariu L'Academia nun recueye bofetón, como si nun fuere asturianu; el DGLLA faelo como llocal de Riosa y Quirós. Sí ta nel mio Diccionariu asturianu castellanu.

${ }^{6}$ DCEHC (1980) = Joan Corominas y José Antonio Pascual, Diccionario crítico etimológico castellano e hispánico, I, Madrid, Gredos, 1980. 
Como quier que seya, la esistencia de bofetón al empar de fobetón plantea una serie de preguntes. Suponiendo que tengan un aniciu onomatopéyicu, ¿parten de dos distintos, fob y bof? ¿Hai que suponer un fobete al pie del antigu bofete castellanu? ¿Represental vocablu asturianu antiguu una metátesis sobre un inicial bofete? ¿Ye al revés? $\mathrm{O}$ lo que nos diz el nuestru *fobete / fobetón ye qu'hai que dir a buscar la etimoloxía n'otru sitiu?

Forse altri canterà con miglior plettro. 
